Vegueta. Anuario de la Facultad de Geografía e Historia

22 (1), 2022, 157-175

eISSN: 2341-1112

https://doi.org/10.51349/veg.2022.1.09

\title{
Estudios digitales fotográficos del Álbum Pintoresco de Canarias de Domingo Bello y Espinosa
}

\author{
Digital photographic studies of the Álbum Pintoresco de Canarias \\ of Domingo Bello y Espinosa
}

\author{
Begoña Pérez-Salvatierra Saavedra* \\ Universidad de La Laguna \\ https:// orcid.org/0000-0002-0118-939X \\ bpss1998@gmail.com \\ Elisa María Díaz González \\ Universidad de La Laguna \\ https://orcid.org/0000-0002-6265-3213 \\ ediazgon@ull.edu.es
}

Recibido: 20/07/2021; Revisado: 26/12/2021; Aceptado: 29/12/2021

\begin{abstract}
Resumen
El avance de las nuevas tecnologías digitales ha desencadenado la evolución de una gran variedad de técnicas utilizadas en el análisis de obras de arte y otros objetos de la cultura material humana. El presente artículo recoge el estudio digital de la técnica pictórica utilizada por el estudioso canario Domingo Bello y Espinosa (1817-1884) en su cuaderno Álbum Pintoresco de Canarias (1879). A partir del uso de la fotografía digital, se desarrolló un primer acercamiento a la caracterización de la técnica de este autor en la realización de sus ilustraciones científicas. Se invita a reflexionar sobre el desconocimiento de ilustraciones del canario y de la utilidad de la tecnología digital en su interpretación.
\end{abstract}

Palabras clave: Fotografía, digitalización, técnica pictórica, Domingo Bello y Espinosa, Álbum Pintoresco de Canarias.

*Autora de correspondencia / Corresponding author.

Copyright: @ 2022 ULPGC. Este es un artículo de acceso abierto distribuido bajo los términos de la licencia Creative Commons Atribución-NoComercial-SinDerivar (by-nc-nd) Spain 3.0. 


\begin{abstract}
Advances in new digital technologies have led to the blossoming of a great variety of techniques for analysing art objects, as well as other elements of material culture. This article outlines a digital study of the artistic technique employed by Canarian naturalist Domingo Bello y Espinosa (1817-1884) in his notebook Álbum Pintoresco de Canarias (1879, whereby digital photography has offered an initial approach to his technique of scientific illustration. The article brings to light this Canarian's heretofore little-known scientific drawings while inviting reflection on the usefulness of digital technology in interpreting them.
\end{abstract}

Keywords: Photography, Digitalisation, Pictorial Technique, Domingo Bello y Espinosa, Álbum Pintoresco de Canarias.

\title{
1. INTRODUCCIÓN
}

Los estudios digitales son aquellos basados en la utilización de mecanismos, sistemas o dispositivos que generan, transmiten y procesan señales informáticas. En el campo del Patrimonio Cultural, el uso de estas técnicas ha supuesto numerosos avances en la difusión, restauración y reconstrucción de diferentes bienes, destacando, concretamente, la fotografía digital.

Ya en los inicios de la fotografía analógica, las obras de arte y bienes patrimoniales eran documentados y estudiados a través de ella, pero es la evolución hacia lo digital lo que permitió precisar y profundizar aún más en estos objetos, obteniendo una mejor calidad de información, detalle y facilidades en la interpretación de las imágenes. Entre las ventajas, podemos destacar que se obtienen resultados de manera inmediata, permiten el estudio con frecuencias lumínicas no perceptibles por el ojo humano y, por último, ofrecen un acercamiento al conocimiento de los materiales, técnicas y degradaciones de la obra. También hay que destacar que muchas de las herramientas digitales son cada vez de más fácil acceso y manejo para todo el público, habiéndose convertido en una parte fundamental e imprescindible en la documentación del Patrimonio Cultural.

A través de esta herramienta digital, se estudiará el Álbum Pintoresco de Canarias, cuaderno de ilustración científica del siglo xIX, realizado por el estudioso Domingo Bello y Espinosa. A él se le atribuyen grandes avances en la botánica y la historia natural de los archipiélagos Canario y de la Macaronesia. «Fue el primer naturalista canario que describió nuevas especies y géneros de plantas y consta como el único canario en la guía botánica Taxonomic Literature II, obra que recopila las biografías y trabajos de los botánicos más importantes del mundo» (SANTIAGO et al., 2013). A pesar de todo, algunas de sus ilustraciones científicas continúan desaparecidas, desconocidas o con autorías erróneas, debido a la inexistencia de estudios relacionados con ellas.

El lector encontrará información acerca de las técnicas fotográficas digitales utilizadas en el estudio e interpretación de las ilustraciones y estado de conservación del manuscrito. Como consecuencia, se comentará la importancia y uso de la calibración del color con una carta Colorchecker, la aplicación del balance de blancos, el uso de la microscopía digital y cómo la utilización de luz transmitida y la luz ultravioleta permiten la caracterización de singularidades de 
esta obra en papel (filigranas, técnicas, dibujos, estado de conservación formación de la pasta de papel, etc.).

El objetivo principal del artículo consiste en la difusión de las características, uso e importancia que ofrecen las técnicas digitales en la investigación de obras de arte, utilizando como ejemplo el caso práctico del estudio de las técnicas y características de las ilustraciones de este naturalista tan importante para la historia de las Islas Canarias y Puerto Rico. A su vez, deja abierto un nuevo campo de investigación que invita a continuar con el estudio en otros manuscritos ilustrados de Domingo Bello y Espinosa y sus estancias en ambos archipiélagos.

\section{DOMINGO BELLO Y ESPINOSA}

Domingo Bello y Espinosa nació en La Laguna en 1817 en el seno de una familia local de la ciudad, hijo de Domingo Bello y Lenard y Ana Espinosa y Carta. Tuvo cuatro hermanos entre los que destacan José Lorenzo (1825-1890) reconocido pintor de la época por sus cuadros religiosos y Jacobina (1815-1889) pintora también de la isla que destacó por sus retratos. En 1842, con 25 años, se doctoró en Derecho por la Universidad de San Fernando de La Laguna y ese mismo año fue nombrado alcalde de la ciudad. Entre 1845 y 1847 fue secretario del Colegio de Abogados de Santa Cruz de Tenerife y en 1848, por motivos desconocidos, emigró a Puerto Rico donde se instaló en la ciudad de Mayagüez. Allí ejerció como abogado y profesor y se casó con la puertorriqueña Leocadia Raldiris Fernández con la que tuvo al menos cuatro hijos, pasando los siguientes 30 años de su vida en esta isla sin regresar a Canarias hasta 1878. Al año siguiente fue nombrado alcalde de su ciudad isleña por segunda vez, aunque renunció a este cargo tres años después por problemas de salud que lo achacan hasta 1884, el año de su fallecimiento (SANTIAGO et al., 2013).

En su estancia en Puerto Rico formó parte de la primera generación de naturalistas junto con el alemán Leopoldo $\mathrm{Krug}^{1}$ y Agustín Stahl, ${ }^{2}$ con quienes se dedicó a realizar los primeros estudios de la historia natural puertorriqueña. A partir de las habilidades adquiridas en estos años escribió Apuntes para la flora de Puerto Rico, publicada en dos partes en 1881 y 1883, lo que lo convirtió en el primer español residente de la isla puertorriqueña que publicó estudios florísticos de Puerto Rico. En ella nombra un nuevo género para un árbol de las Antillas y 8 nuevas especies de las cuales 6 son endémicas de Puerto Rico. Además, ésta es una de las obras más importantes para la isla caribeña, siendo uno de los primeros trabajos formales sobre la botánica puertorriqueña. (SANTIAGO et al., 2013). Formó parte, por tanto, de la primera generación de residentes estudiosos de la isla que fomentaron la "edad dorada" de la botánica del archipiélago (SANTIAGo et al., 2015). Estas contribuciones tienen mayor importancia teniendo en cuenta que se realiza en un momento en el que Puerto Rico no ofrece universidades, museos o sociedades científicas de ninguna clase y que, por lo tanto, el estudioso

1 Carl (o Karl) Wilhelm Leopold Krug (1833-1898): entre otras profesiones diplomático alemán en la legación germana de Puerto Rico (1857-1867) donde realizó numerosas expediciones botánicas. Su material fue la base del Herbario Krug y Urban destruido en la Segunda Guerra Mundial.

2 Agustín Stahl (1842-1917): médico-cirujano, naturalista, etnógrafo y practicante de la taxonomía zoológica y botánica, considerado como el primer científico puertorriqueño y autor de Estudios sobre la flora de Puerto Rico (1883-1888). 
no tuvo acceso a las obras más relevantes de la bibliografía botánica de la época (SANTIAGo et al., 2013). Según el estudio realizado por Eugenio Santiago-Valentín, Lázaro Sánchez-Pinto y Javier Francisco-Ortega en Domingo Bello y Espinosa: desde Canarias a las Antillas, se comenta cómo seguramente la amistad de Bello con Leopold Krug y el trabajo en conjunto en sus exploraciones botánicas, compensa esa falta de recursos. Por último, cabe mencionar que el canario se preocupaba también de los estudios zoológicos, siendo «el primer naturalista que descubrió que ciertos anfibios ranuros ${ }^{3}$ carecen de fase de metamorfosis en agua y de etapa como renacuajos en ambiente libre» (SANTIAGO et al., 2013).

En su regreso a Canarias en 1878, formó parte del grupo de intelectuales y literarios de la época, creando amistades y coincidiendo con personajes como Juan Bethencourt Alfonso, ${ }^{4}$ Diego Crosa y Costa, ${ }^{5}$ Luis Maffiotte La Roche ${ }^{6}$ y otros, entre los que también podemos nombrar al farmacéutico Eduardo Rodríguez Núñez, gran pintor y amante de la naturaleza y la botánica. Hay constancia de que Bello tenía la intención de actualizar e ilustrar el Diccionario de historia natural de Viera y Clavijo, trabajo que llevaba realizando, según Ramón Masferrer i Arquimbau, ${ }^{7}$ desde 1866. Sin embargo, falleció antes de poder finalizarlo conservándose los manuscritos en colecciones privadas y públicas (FRANCISCO et al., 2019/2020).

Entre sus aportaciones a esta élite de literarios en el archipiélago, cabe destacar sus publicaciones en revistas canarias como La Revista de Canarias, Museo Canario e Ilustración de Canarias en las que publicó numerosos artículos y relatos de interés artístico, científico y naturalista. La Revista de Canarias publica entre 1879 y 1880 su obra más conocida relacionada con el archipiélago canario y su flora: Un jardín canario, dividido en 10 capítulos y en el que se narra el recorrido por un jardín canario imaginario situado en la ciudad China de Shanghái (FRANCISCO et al., 2019-2020).

Bello continuó manteniendo relación de amistad con sus amigos de las Antillas, lo que contribuyó a que algunos de ellos visitaran las islas, promoviendo de esta manera el estudio de algunos de los ámbitos naturales del archipiélago. Cabe destacar la aportación de su amigo naturalista y ornitólogo alemán Juan Cristóbal Gundlach (1810-1896), que publicó un trabajo sobre las aves de Canarias en la Revista de Canarias en 1879 (FRANCISCO et al., 2019-2020).

En conclusión, Domingo Bello y Espinosa fue un gran erudito y estudioso que se preocupó por el desarrollo y expansión del conocimiento natural en la sociedad. Fue de gran importancia para las Islas Canarias y Puerto Rico, gracias al cual se le deben atribuir grandes avances en la botánica y la historia natural de ambos archipiélagos (Canario y la Macaronesia). A todo lo anterior, también hay

3 Estas observaciones son sobre la rana arbórea endémica de Puerto Rico Eleutherodactylus coqui. Las ranitas, que se desarrollan en huevos depositados sobre hojas de determinadas plantas, nacen como individuos de tamaño reducido, pero con una morfología idéntica a la de las adultas.

4 Juan Bethencourt Alfonso (1847-1917): médico, antropólogo y periodista canario que destaca entre otros logros por ser el autor de Historia del pueblo guanche.

5 Diego Crosa y Costa («Crosita») (1869-1942): importante poeta, periodista y pintor de la isla de Santa Cruz de Tenerife.

6 Luis Maffiotte La Roche (1862-1937): bibliográfico y periodista canario que destaca por sus estudios bibliográficos sobre Canarias y la creación en 1895 de una Biblioteca de Canarias.

7 Ramón Masferrer i Arquimbau (1850-1884): médico militar español que destaca por sus estudios botánicos en Osona (Barcelona), con la publicación de Recuerdos botánicos de Vich, la primera monografía botánica de la comarca. También estudió la botánica de Canarias y Filipinas, realizando numerosas publicaciones. 
que añadir, que no sólo fue el primer naturalista canario que describió nuevas especies y géneros de plantas, sino que también consta como el único canario en la guía botánica Taxonomic Literature II.

\subsection{Ilustraciones de Bello en la isla de Tenerife}

Domingo Bello y Espinosa fue un gran ilustrador de especies tanto botánicas como zoológicas, llevando a cabo la realización de bocetos y dibujos que ilustran con gran exactitud las características de las especies que estudia. Es por ello por lo que sus dibujos se pueden incluir dentro de la denominada Ilustración Científica, término utilizado para aquellas ilustraciones cuyo principal objetivo es representar mediante un dibujo detallado una idea, reafirmando visualmente textos científicos y comunicando una información concreta (SÁNCHEZ y BARROSO, 2014).

Gracias a los recientes estudios dedicados a su biografía y obra, se desarrollaron una serie de descubrimientos de manuscritos e ilustraciones de flora y fauna que Bello realizó durante su segunda estancia en las islas (1878-1884), conociéndose un total de 5 conjuntos de manuscritos e ilustraciones custodiados en archivos privados y públicos en la isla de Santa Cruz de Tenerife: dos conjuntos de manuscritos e ilustraciones custodiados en las entidades públicas (apuntes legados de Miguel T. G. en la Biblioteca de la Universidad de La Laguna e ilustraciones y manuscritos en el Museo de Bellas Artes) y tres en colecciones privadas (Pedro Tarquis y Fariña, profesor Alfonso Morales y Morales y profesor Manuel J. Hernández González) (FrANCISCO et al., 2019/2020).

Sin embargo, a falta del conocimiento del legado de los estudios botánicos de este naturalista para la isla tinerfeña, existe un vacío en cuanto a estudios sobre sus ilustraciones y su técnica artística. Como consecuencia, muchas de sus obras fueron confundidas con acuarelas y dibujos de otros autores. El ejemplo lo encontramos en la antigua atribución del conjunto de acuarelas y dibujos custodiados en el archivo privado de los herederos del profesor de Farmacia Alfonso Morales y Morales a la autoría de Eduardo Rodríguez Núñez. Alfonso Morales y Morales llegó a publicar en el periódico La tarde una biografía de este autor donde incluyó la acuarela de la cresta de gallo (Isoplexis canariensis) como suya (FRANCISCO et al., 2019-2020). En la publicación de Rincones del Atlántico $\mathrm{N}^{\mathrm{O}}$ 10, se explica cómo posteriormente Alfonso Morales y Morales y Pedro Tarquis Rodríguez comprobaron una incoherencia entre las fechas de realización de estas ilustraciones con la biografía de Núñez, ya que estaban fechadas en 1866 y 1867, fechas en las que este personaje sólo era un niño de 10 años. Ocurre lo mismo con un segundo juego de ilustraciones de Pedro Tarquis y Fariña fechadas en esos años. Entre estas fechas, seguramente llevó a cabo más ilustraciones del archipiélago.

Es importante comentar también el conocimiento de la existencia de apuntes desaparecidos de Bello y Espinosa relacionados con la copia custodiada por la Biblioteca de Canarias de la Universidad de La Laguna y parte del legado de Miguel Tarquis García (1923-1968):

Se titula Apuntes botánicos de las islas Canarias II y está firmado en Tegueste en los meses de agosto, septiembre y octubre de 1878. Por este título parece que estos Apuntes tuvieron varias partes, pero hasta el momento solamente hemos localizado 
la segunda. Este manuscrito es una copia del original, hecha en mayo de 1948, pero desconocemos quién fue el autor (FRANCISCO et al., 2019-2020).

Sin embargo, existe la certeza de que el original fue producido por Bello, ya que contiene referencias a acuarelas hechas y numeradas por él, pertenecientes al archivo privado de Pedro Tarquis Fariña. (FrANCISCO et al., 2019/2020).

Estos datos nos permiten observar el todavía desconocimiento de obras de este naturalista. Es por ello por lo que a partir de la oportunidad de estudiar el conjunto de ilustraciones perteneciente a la colección privada del profesor Manuel J. Hernández González (Album Pintoresco de Canarias), se inició una investigación sobre las características estilísticas de una de sus obras, comparándolas con algunas de sus ilustraciones en entidades públicas a nuestro alcance (Museo de Bellas Artes de Santa Cruz de Tenerife).

\section{EL ÁLBUM PINTORESCO DE CANARIAS}

El cuaderno manuscrito titulado Álbum Pintoresco de Canarias, firmado en La Laguna en el año 1879 y perteneciente al historiador Manuel J. Hernández González, quien adquirió el cuaderno a través de un regalo por parte de unos parientes descendientes de Domingo Bello y Espinosa, concretamente de Antonio Rodríguez Bello, sobrino nieto de Bello y Espinosa (FRANCISCO et al., 2019-2020).

El cuaderno contiene una serie de dibujos científicos de flora y fauna canaria realizado por Domingo Bello y Espinosa que forman en total 35 ilustraciones de especies vegetales, de las cuales 9 son endémicas del archipiélago como por ejemplo el pico de paloma -Lotus berthelotii-, la gomereta -Navaea phoenicea- o la orijama - Neochamaelea pulverulenta- y 4 de la Macaronesia. También contiene acuarelas de un caracol terrestre, 25 lepidópteros, un perenquén, 13 aves, un paisaje de las Cañadas del Teide y dos mapas del archipiélago, incluyendo asimismo varias notas manuscritas del estudioso (FRANCISCO et al., 2019/2020).

En cuanto a las características físicas del cuaderno, presenta unas dimensiones de 28,2 $\mathrm{cm} \times 22,2 \mathrm{~cm}$, midiendo los folios del interior $27,8 \mathrm{~cm} \times 21$ $\mathrm{cm}$. Se puede observar que presenta una encuadernación original con cubiertas de tipología acartoné y un lomo forrado en cuero, siendo notable la presencia de un añadido de papel marmolado verde. Debido al desgaste de algunas zonas de la encuadernación, es posible divisar el papel blanco con pintas azules y las cantoneras de tela marrón de las esquinas de la cubierta original. Pegada en el centro superior de la portada se encuentra una cartela con el título del cuaderno. El interior está formado por 90 folios de papel continuo de los cuales 38 están ilustrados, aunque también hallamos hojas independientes con características diferentes que el autor utilizó para realizar apuntes sueltos. Por último, en relación con su estado de conservación, se pueden mencionar algunos daños puntuales en la cubierta como rayaduras, incisiones y desgastes, así como pequeñas pérdidas del papel añadido. Por otro lado, las hojas del interior se encuentran en buen estado de conservación a pesar de la fragmentación de un cuadernillo en una de sus hojas, leves dobleces y pequeños desgarros, además de un amarilleamiento del papel producido por la oxidación. En resumen, a pesar de presentar leves degradaciones, el cuaderno se encuentra en un buen estado de conservación (Pérez-Salvatierra, 2020). 


\section{METODOLOGÍA}

En el estudio del patrimonio cultural, los estudios digitales han supuesto un gran avance en el examen de los materiales que conforman una obra de arte. Su gran ventaja reside en que permiten acceder a detalles característicos de la obra sin necesidad de entrar en contacto directo con ella. Al crear una imagen digital en un dispositivo, ésta puede ser editada en diferentes softwares que permitan realizar gráficas, mapeo de daños, aumentos de detalles, panorámicas e incluso combinarse con diferentes imágenes realizadas en los diferentes espectros de luz (técnicas Multibanda). Todo ello abre un abanico de posibilidades que arrojan información detallada y documenta las características de la obra estudiada y del estado de conservación en el que se encuentra. Además, pueden utilizarse para la obtención de las primeras hipótesis para la identificación de pigmentos históricos o del resultado esperado en una intervención, aunque siempre se deben contrastar con posteriores pruebas y analíticas.

Los estudios digitales engloban una gran variedad de técnicas (estudios Multibanda, termofotografía, colorimetría, recreaciones 3D...) con sus respectivas herramientas, que nos transmiten la información necesaria dependiendo del objeto que se estudia. En nuestro caso de estudio, por tratarse de papel translúcido y sin necesidad de indagar profundas capas de material, nos centramos en las técnicas fotográficas dentro del espectro visible y en el espectro ultravioleta (UV). Sin embargo, otras técnicas del Multibanda (Infrarrojo o Infrarrojo de Falso Color, por ejemplo) podrían también arrojar abundante información.

\subsection{Digitalización}

Con «proceso de digitalización» en el ámbito de Patrimonio Cultural, nos referimos al proceso por el que un documento es fotografiado para la obtención de una copia digital. Se trata de una acción preventiva o de conservación intelectual de lo recogido en estos documentos. Gracias a ella, muchos documentos archivísticos y obras gráficas han podido conservarse tras el paso de los años y ser estudiadas sin dañar la obra original al ser consultada. A través de la digitalización, los datos visualizados permiten analizar, representar y comunicar el pasado y el presente, características que coinciden con la metodología de trabajo de la Historia digital.

A pesar de que la digitalización, como comentamos, en lo que a nuestra investigación le concierne, esta herramienta no nos transmite toda la información requerida debido a que su objetivo se reduce a los datos representados y no a los materiales, técnicas o estado de la obra. Por estos motivos, a pesar de que las ilustraciones fueron en su momento digitalizadas por el Centro de Documentación de Canarias y América (CEDOCAM) en el año 2015, hemos vuelto a fotografiar el álbum con el fin de obtener mayor textura e información en la exposición de la imagen a diferentes iluminaciones y radiaciones electromagnéticas. 


\subsection{Fotografía de las ilustraciones}

\subsubsection{Espectro visible}

El principio que permite al sistema visual humano observar el mundo se basa en la reflexión de la luz de los objetos. Pero esta luz forma parte sólo de una pequeña porción del espectro electromagnético (EM), un conjunto de ondas electromagnéticas variables de electricidad y magnetismo que se distinguen por su longitud. El ojo humano sólo puede percibir una pequeña porción de este espectro, al que denominamos luz visible y comprende aproximadamente las luces con ondas entre 400 y 700 nanómetros. Para detectar la radiación óptica en un dispositivo que documente una imagen es necesario transformar la radiación EM en una señal digital. Los detectores de esta señal los encontramos en los fotodetectores de las cámaras fotográficas digitales, que revelan la radiación y generan información en función de la longitud de onda del EM recibido (VERHOEVEN, 2016, 131). A la hora de fotografiar hay que tener en cuenta tres factores fundamentales para el ajuste pertinente de los parámetros de formación de una imagen de calidad: 1. la radiación que ilumina el objeto va a crear una radiación electromagnética determinada, 2. el objeto presenta sus propias características reflectantes y 3. el sensor receptor también interpreta en función de su propia configuración. (VERHOEVEN, 2016, 138-139).

Teniendo en cuenta estos principios, el álbum se fotografió con una cámara digital Nikon D3100 utilizando el formato RAW. Para una mayor precisión del color se realizó una calibración colorimétrica y balance tonal mediante la herramienta ColorChecker Passport. La necesidad de esta última herramienta reside en la característica de que el ojo humano forma los colores en función de tres canales, uno para cada color: RGB (Red/Green/Blue). Para que la percepción de nuestro ojo sea simultánea a los canales recogidos por el sensor de la cámara, que presenta su propio espacio de color, es necesaria una herramienta colorimétrica (VERHOEVEN, 2016, 151-152). La ColorChecker Passport está enfocada a corregir ajustes cromáticos (matices) mediante muestras de color, y ajustes acromáticos (luminosidad y exposición) mediante sus muestras de grises. La carta de color permite, por tanto, calibrar los colores una vez fotografiado el objeto tras ser procesado en el ordenador, lo que nos permite obtener imágenes colorimétricamente más fieles a la realidad (PEREIRA, 2017).

El resultado final son fotografías de calidad donde se observan las ilustraciones y las degradaciones que producen sobre el soporte de papel. Con este primer acercamiento podemos deducir que el autor utiliza diferentes técnicas por la forma en que distintas zonas del reverso de cada página actúan ante el contacto con determinados elementos aplicados para colorear las ilustraciones. También se documenta que Domingo Bello y Espinosa realiza primeramente un boceto con lápiz de grafito antes de dar color a las especies que quería representar.

\subsubsection{Macrofotografía}

Dentro del espectro visible, la utilización de diferentes lentes o enfoques en la cámara o dispositivo permiten obtener diversos resultados de lo fotografiado. Un ejemplo es el uso de la macrofotografía, que consiste en el agrandamiento 
de la imagen real hasta 10 veces su tamaño obteniendo información aislada de detalles de interés específico, como puede ser el tamaño de los pigmentos utilizados o pequeñas degradaciones del soporte. Para un mayor acercamiento a la composición y aplicación de los procedimientos, el uso del microscopio Digital Microscope Jiusion ayudó a la realización de la fotografía macro en diferentes puntos de las ilustraciones.

Gracias a este método analítico se pudo documentar la granulometría en algunos puntos de las técnicas utilizadas, lo que permitió obtener información específica. Por ejemplo, podemos observar que utiliza una técnica donde se aprecia el uso de diferentes pigmentos de una granulometría gruesa y opaca que contrasta con las zonas donde se aplica la acuarela (pigmento fino, bien adherido y con superposiciones de capas). Este procedimiento podría tratarse de gouache, ya que es conocido que se incorpora un pigmento o carga blanca en su composición para conseguir un efecto opaco. Por último, también permitió ver la aplicación de una capa de material que produce un resultado brillante en algunas de las ilustraciones, como por ejemplo en el ojo de los pájaros del dibujo de la Fringilla carduelis, Lin (pág 10 del álbum) o las flores blancas de Periplora laevigata (pág. 12 del álbum).

\subsubsection{Luz transmitida}

Como en el caso anterior, dentro de los estudios realizados con luz visible, ésta puede ser aplicada desde diferentes ángulos y ofrecernos más información sobre el objeto estudiado. El estudio con luz transmitida consiste en el uso de la luz de tal manera que atraviese el objeto desde su anverso. Es una técnica que arroja información acerca de la composición del soporte y su estado de conservación. En los estudios de los materiales con soporte de papel, es una técnica muy utilizada debido a la naturaleza translúcida de estos objetos, permitiéndonos conocer la disposición y características de las fibras, la tipología de fabricación del papel (continuo o artesanal) o si presenta filigranas que pueden ayudar a determinar su datación y origen. La fotografía de estas características es enormemente útil para documentar y minimizar la posterior manipulación. También esclarece las posibles degradaciones como dobleces, desgarros o roturas con más facilidad y ayuda a conocer la opacidad de los elementos sustentados y su aplicación.

Para este estudio, la luz transmitida se aplicó con ayuda de un negatoscopio, una mesa que transmite un foco de luz que pasa a través de un cristal o superficie translúcida sobre la que se coloca la obra a estudiar. Bajo esta luz se colocaron aquellas hojas manuscritas independientes que se encontraban dispersas entre las páginas. Éstas, se numeraron según el número de la página del álbum en la que se encontraban $\left(n^{\circ} 30, n^{\circ} 31, n^{\circ} 35\right.$, etc.) para identificarlas y definirlas.

El resultado fue la distinción de la disposición de la fibra en el papel permitiendo observar que son de fabricación mecánica y con acabado vitela, aunque el $n^{\circ} 39$ presenta un acabado verjurado. También se pudo comprobar que cuatro papeles presentaban una filigrana: el $n^{\circ} 10, n^{\circ} 31, n^{\circ} 34$ y $n^{\circ} 39$. Sin embargo, debido a que están incompletas $\left(n^{\circ} 10\right.$ y $\left.n^{\circ} 34\right)$ o son ilegibles, no fue posible identificarlas. También permitió obtener información sobre la aplicación de los procedimientos, como se puede ver en el folio $\mathrm{n}^{\circ} 10$. 


\subsubsection{Espectro ultravioleta}

El uso de técnicas digitales fotográficas dentro del espectro visible, permiten caracterizar muchos aspectos de la obra. Por otro lado, estos estudios pueden compararse con otros realizados en un EM diferente y no visible, pudiendo ayudar a la caracterización de los procedimientos aplicados en las ilustraciones.

La luz ultravioleta (UV) es una de las radiaciones que se encuentran fuera del espectro visible, y su longitud de onda oscila entre 10 y 400 nanómetros. $\mathrm{Su}$ radiación permite excitar determinadas sustancias, creando un fenómeno de fluorescencia, lo que produce una respuesta por parte de los materiales, que devuelven la energía a través de longitudes de onda distintas que son percibidas por nuestros ojos como distintos colores (COSENTINO, 2015). En el estudio relacionado con la conservación y restauración de papel, sobre todo se utiliza para leer manuscritos con tinta desvaída o estudiar la oxidación y degradación (CONTRERAS Y BECERRA, 2020).

En nuestro caso, las diferentes reacciones de los materiales a esta radiación nos proporcionaron ayuda en la identificación de las zonas en las que se utilizaron diferentes procedimientos. En el reverso de las ilustraciones fue muy útil para delimitar aquellos puntos más afectados por las degradaciones del soporte y distinguir dónde se aplicaron las diferentes técnicas. También fue muy importante la fluorescencia emitida de los pigmentos, ya que nos permitió comparar las diferentes ilustraciones entre ellas y acercarnos a una hipótesis sobre algunos pigmentos y aglutinantes presentes en los dibujos. Sin embargo, sólo permite suposiciones, ya que para conocer específicamente el pigmento o el aglutinante utilizado sería necesario realizar otras pruebas más enfocadas a ello, como podrían ser la espectroscopía infrarroja de Fourier (FTIR) o la Espectrometría Raman (CONTRERAS y BECERRA, 2020), por ejemplo.

Las imágenes se compararon con las realizadas en la luz visible, permitiendo caracterizar algunos procedimientos utilizados. En primer lugar, las zonas con degradaciones que producían una reserva en el reverso de los folios (aquellas que bajo luz visible son más blancas) y acidez (bajo luz visible más oscuras) se pudieron visualizar de manera más exacta la fluorescencia emitida. Bajo luz UV en el caso de la acidez, se emite un color más violáceo y en las zonas con reserva, uno más blanco. Se distinguieron también dos tipos de fluorescencias relacionadas con el pigmento blanco: una que emite una fluorescencia más blanca y brillante que contrasta con otra más opaca y de color más cálido. Estos resultados permiten tres identificaciones: en primer lugar, podría tratarse de blanco de plomo, considerado el pigmento más claro utilizado por excelencia durante la historia y que bajo luz UV presenta una fluorescencia blanca, pero, dependiendo del aglutinante utilizado puede variar y ser más azulada o amarillenta. Por otra parte, el blanco de plomo resulta de color amarillento claro bajo UV. Sin embargo, por otro lado, el blanco de litopone presenta un comportamiento parecido, por lo que sería necesario comparar estas apreciaciones con técnicas complementarias (RAÏcH et al., 2019).

En segundo lugar, se puede apreciar la presencia del uso de un pigmento base que emite una fluorescencia opaca que aplica sobre zonas normalmente verde ya coloreadas. Por último, se identificó el uso de un pigmento amarillo que utiliza en el higo tuno o las alas de una mariposa (láminas 16, 18 y 19), que produce una fluorescencia amarilla anaranjada. Bajo luz visible, las zonas donde se aplica 
este pigmento son de color amarillo anaranjado, por lo que si fuese una laca, cabe la posibilidad de que se trate de la laca amarilla o yellow lake, un pigmento «resistente a la luz, transparente, formado a partir del extracto de corteza de roble (quercitron) precipitado en alumbre o tiza, que fue utilizado en el siglo XVII, a menudo en mezclas con azul para producir un color verde oscuro». ${ }^{8}$ Sin embargo, estas identificaciones de pigmentos sólo son hipótesis y sería necesario realizar estudios más específicos y que permitan contrastar diferentes resultados.

\section{RESULTADO FINAL DE LOS ESTUDIOS}

Las ilustraciones que contiene el álbum son tanto bocetos a lápiz como láminas coloreadas realizadas por una sola cara de las páginas y sobre papel continuo (sin características especiales para ninguna técnica pictórica en concreto). El estudioso dibujó primero la figura a representar que luego coloreó con una primera capa de color (probablemente con acuarela) y sobre ésta aplicó otros elementos sustentados de características más opacas (podrían ser gouaches o ceras) para conseguir más contraste o brillos en algunos detalles. Este procedimiento lo vemos en la mayoría de las ilustraciones, pero destaca en la realización de las alas de las mariposas, las flores o en algunas hojas de plantas. En algunos casos, como en el de los pájaros cochinos o la imagen del Teide, utiliza diferentes pigmentos blancos, seguramente, por las fluorescencias obtenidas. Además, también nos encontramos con una técnica de acabado brillante en algunos puntos como el ojo de un pájaro (Fringilla carduelis, Lin. (Pintado, Jilguero) o las alas de una mariposa (Pyrameis Callirhoe, Hubu) utilizado como detalles específicos. Por último, se puede comprobar la utilización de un elemento sustentado de color verde claro y tonalidad ocre que aplica sobre las superficies que colorea de verde. Es bastante característica la degradación producida por este procedimiento en el soporte, pues da lugar a una oxidación en la zona aplicada.

Cabe destacar también una pequeña curiosidad que demuestra el interés de Bello por probar y mezclar técnicas: en la página 14, una de las mariposas pertenecientes al grupo de las Macroglossa stellatarum, L. presenta en las alas, una decoración con pan de oro (lámina 21).

Las ilustraciones del Álbum Pintoresco de Canarias fueron comparadas con las custodiadas en el Museo de Bellas Artes de Santa Cruz de Tenerife ${ }^{9}$ (observadas bajo luz visible) con el objetivo de determinar las similitudes y diferencias existentes entre ellas. Fruto de esta comparación es la definición de 4 características que describen su técnica:

1. El uso de un elemento sustentado de color verde con una tonalidad ocre y de base acuosa que se aplica sobre zonas normalmente verdes como segunda capa. Este elemento se oxida tanto por el reverso de la página como el de la hoja anterior, llegando en algunos casos a traspasar los folios posteriores transmitiendo acidez a las ilustraciones siguientes.

2. Utiliza dos pigmentos blancos, uno de ellos para pequeñas áreas y detalles que produce una reserva en el reverso de la hoja en la que se encuentra y, por otro

8 Centro de Documentación de bienes patrimoniales. Tesauro de Arte y Arquitectura, Laca amarilla. Recuperado en 8 de Julio de 2021, de https:/ / www.aatespanol.cl/terminos/300014006

9 Las ilustraciones pertenecientes al Icones florae Puertoricenis y a los 14 cuadernillos separados por diferentes especies de plantas separadas por familias. 
lado, acidez en la anterior.

3. Las zonas con pigmentos marrones y negros presentan (cuando no es acuarela) una textura que recuerda a la cera, dejando una reserva en el reverso de la página. Esta textura se repite para los tonos amarillos empleados, pero sin llegar a producir una degradación visible.

4. Aplica una laca brillante y transparente para destacar pequeños detalles como el ojo de un pájaro o las alas de una mariposa.

\section{CONCLUSIONES}

El objetivo principal del artículo, difundir el conocimiento acerca de las herramientas de fotografía digital en el estudio de obras de arte, ha demostrado cómo con la posesión de pocas herramientas (una cámara digital, lámparas de luz UV, un negatoscopio y un microscopio USB), se puede realizar un primer acercamiento al estudio de nuestro patrimonio. El hecho de que estas técnicas sean accesibles, no invasivas y económicas, son de gran utilidad para aquellas instituciones, museos y bibliotecas que no cuentan con la posibilidad de acceso a otras herramientas para el análisis científico. Por otro lado, hay que puntualizar, que esta tipología de estudios lleva detrás un trabajo realizado por personal cualificado y dotado en conocimientos de fotografía y conservación de bienes culturales que conocen la forma correcta de actuación: cómo manipular estos objetos, qué información es necesaria obtener, qué pruebas y analíticas son recomendadas y cómo se analizan los datos recogidos siempre en contraste con un equipo interdisciplinar.

La importancia de los resultados obtenidos en este estudio también reside en que las fotografías resultantes protegen al manuscrito, reduciendo el número de veces que será manipulado en futuros estudios. A su vez, a la hora de que se vea la necesidad de tomar muestras, esta documentación ayuda a justificar la toma, la localización y su cantidad. Hay que recordar también, que sirven de documento ilustrativo de las hipótesis, actuaciones, propuestas y resultados obtenidos.

En conclusión, mediante el estudio de las técnicas pictóricas y el estado de conservación del manuscrito Álbum Pintoresco de Canarias se ha podido mostrar las ventajas que estas herramientas de fotografía digital aportan a la documentación, estudio y conservación del patrimonio. Es importante comentar que los resultados obtenidos necesitan ser contrastados con otros estudios que caractericen definitivamente la técnica y procedimientos de este naturalista. Por ello, para terminar, el presente artículo digital espera servir también como herramienta de estudio para aquellos interesados en la historia de Canarias y, en específico del personaje en cuestión: Domingo Bello y Espinosa. Esperamos que aquellas obras desconocidas salgan a la luz y puedan ser conservadas, estudiadas y difundidas como el importante legado que son.

\section{AGRADECIMIENTOS}

Agradecemos a Manuel J. Hernández González la confianza para el estudio de este manuscrito, así como por su disponibilidad y apoyo. También al Museo de Bellas Artes de Santa Cruz de Tenerife el acceso a los manuscritos de Domingo 
Bello y Espinosa que mantiene tan cuidadosamente conservados. Al CEDOCAM por permitirnos el acceso a los documentos digitalizados.

\section{RECURSOS WEB}

Biografía. Galería de Metges Catalans. «Ramón Masferrer i Arquimbau». Recuperado el 20 de abril de 2020 de http:/ / www.galeriametges.cat/galeriafitxa.php?icod=FKF.

Biografías y Vidas. La enciclopedia biográfica en línea. «Antonio José Cavanilles». Barcelona (España). Recuperado el 20 de abril de 2020 de https://www. biografiasyvidas.com/biografia/c/cavanilles.htm el.

Centro de Documentación de bienes patrimoniales. Tesauro de Arte y Arquitectura. «Laca amarilla» Recuperado el 8 de Julio de 2021 de https:/ / www.aatespanol.cl/terminos/300014006.

PEREIRA,J.(2017): «ControldelaescenaconColorCheckerPassport».Archivodevídeo recuperado de https:/ / www.youtube.com/watch?v=4hqdOkOecW4\&t=5s.

Ruiza, M., Fernández, T. y TAMAro, E. (2004): «Biografía de Carl von Linné (Linneo)», en Biografías y Vidas. La enciclopedia biográfica en línea. Barcelona (España) Recuperado el 20 de abril de 2020 de https:/ / www.biografiasyvidas. com/biografia/l/linne.htm.

StAhl, A. «Flora of Puerto Rico and the virgin islands», en Smithsonian, National Museum of Natural History. Department of Botany. Recuperado el 20 de abril de 2020 de https://naturalhistory.si.edu/research/botany/research/ florapuerto-rico-and-virgin-islands/augustin-stahl el.

\section{REFERENCIAS}

Cosentino, A. (2015): «Practical notes on ultraviolet technical photography for art examination», Conservar Património, 21: 53-62. https:/ / doi.org/10.14568/ cp2015006

CONTRERAS, G.M.; BeCERRA, J. (2020): «Técnicas analíticas para la caracterización de documentos: una revisión bibliográfica», Ge-Conservacion, 17 (1): 251-266. https://doi.org/10.37558/gec.v17i1.760.

Francisco, J.; SANTIAGO, E.; SANTOS, A. et al. (2019-2020): «Domingo Bello y Espinosa en las islas Canarias: la obra de un gran naturalista y humanista. Un homenaje en el 200 aniversario de su nacimiento», Rincones del Atlántico, 10: 98- 114.

Pérez-Salvatierra, B. (2020): Estudio y propuesta de restauración del Álbum Pintoresco de Canarias, Trabajo de Fin de Grado en Conservación y Restauración de Bienes Culturales, Universidad de La Laguna.

RAïch, M.; Artoni, P.; Herrero, M.A.; La Bella, A. (2019): «Riconoscere dal colore. Pigmenti e coloranti dell'età moderna nell'analisi multibanda dei dipinti: uno strumento visivo per gli storici dell'arte e i conservatori», en Colore e Colorimetria. Contributi Multidisciplinari, vol. XV, Milano.

SÁNCHEZ, M.E.; BARROSO, C. (2014): «La ilustración científica y su aplicación como herramienta visual en la cartografía novohispana», Investigación y Ciencia, 22 (63): 80-87.

SAntiago, E.; SÁnchez, L.; Francisco, J. (2013): «Domingo Bello y Espinosa: desde 
Canarias a las Antillas. Estudio de la flora de Puerto Rico en el siglo XIX», Makaronesia: Boletín de la Asociación de Amigos del Museo de Ciencias Naturales de Tenerife, 15: 162-175.

VALEnTín, E.S.; SÁNCheZ, L.; Francisco, J. (2015): «Domingo Bello y Espinosa (18171884) and the new taxa published in his Apuntes para la flora de Puerto Rico», Taxon, 64 (2): 323-349.

SEYMOUR, K. (2010): «Standard non-destructive techniques used to document and examine artworks employed within the conservation field», Presentation at the International Symposium on Cultural Heritage Conservation: Non-destructive testing technology application (Taiwan, 6-7 December 2010).

Verhoeven, G. (2012): «Methods of visualisation», en E. Howell y P. VANDENABeEle (eds.), Analytical Archeometry: Selected Topics, Royal Society of Chemistry, London: 3-48.

Verhoeven, G. (2016): «Basics of Photography for Cultural Heritage Imaging», in E. StYlianidis y F. Remondino, F. (eds.), 3D Recording, Documentation and Managed of Cultural Heritage, Whittles Publishing, Caithness: 127-251. 

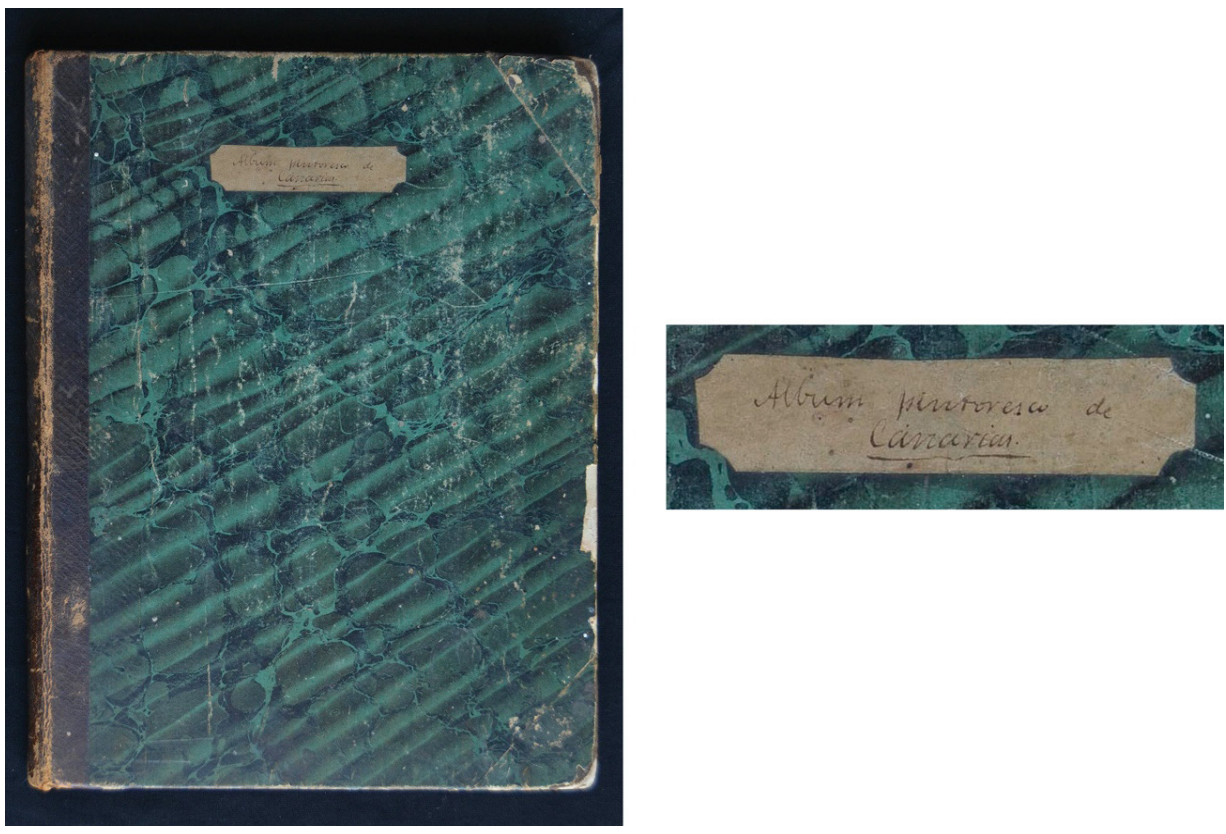

Figura 1. Imagen de la cubierta del Álbum Pintoresco de Canarias donde se aprecian las características de la encuadernación y su estado de conservación (izquierda). Detalle de la cartela de la cubierta principal con el título del cuaderno (derecha). Fuente: Autoras.
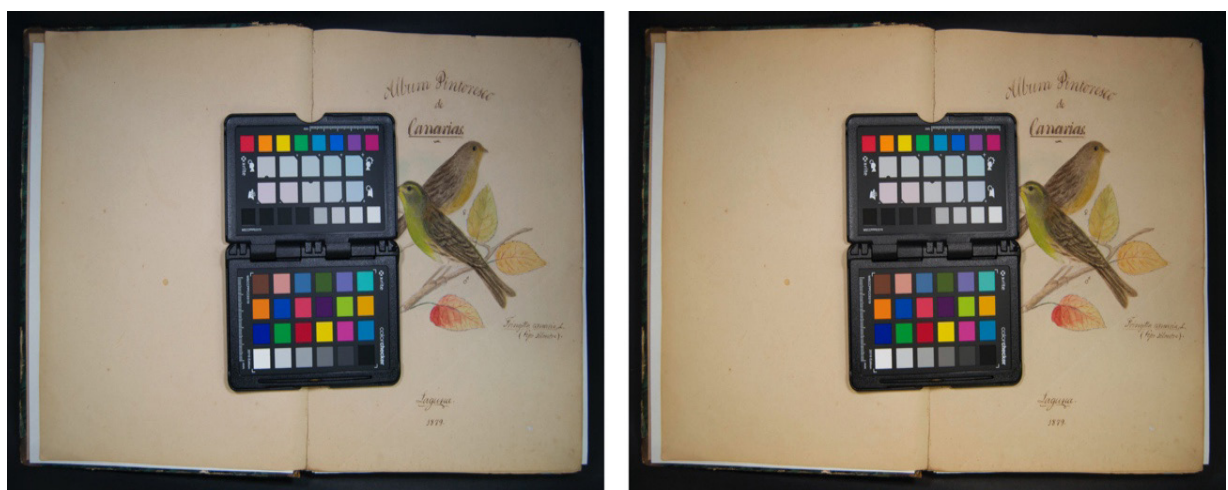

Figura 2. Fotografía de la primera ilustración del álbum con la carta de color ColorChecker Passport antes de la calibración del color y del balance de blancos (izquierda). Resultado de la calibración del color y del balance de blancos realizada en la imagen anterior (derecha). Fuente: Autoras. 


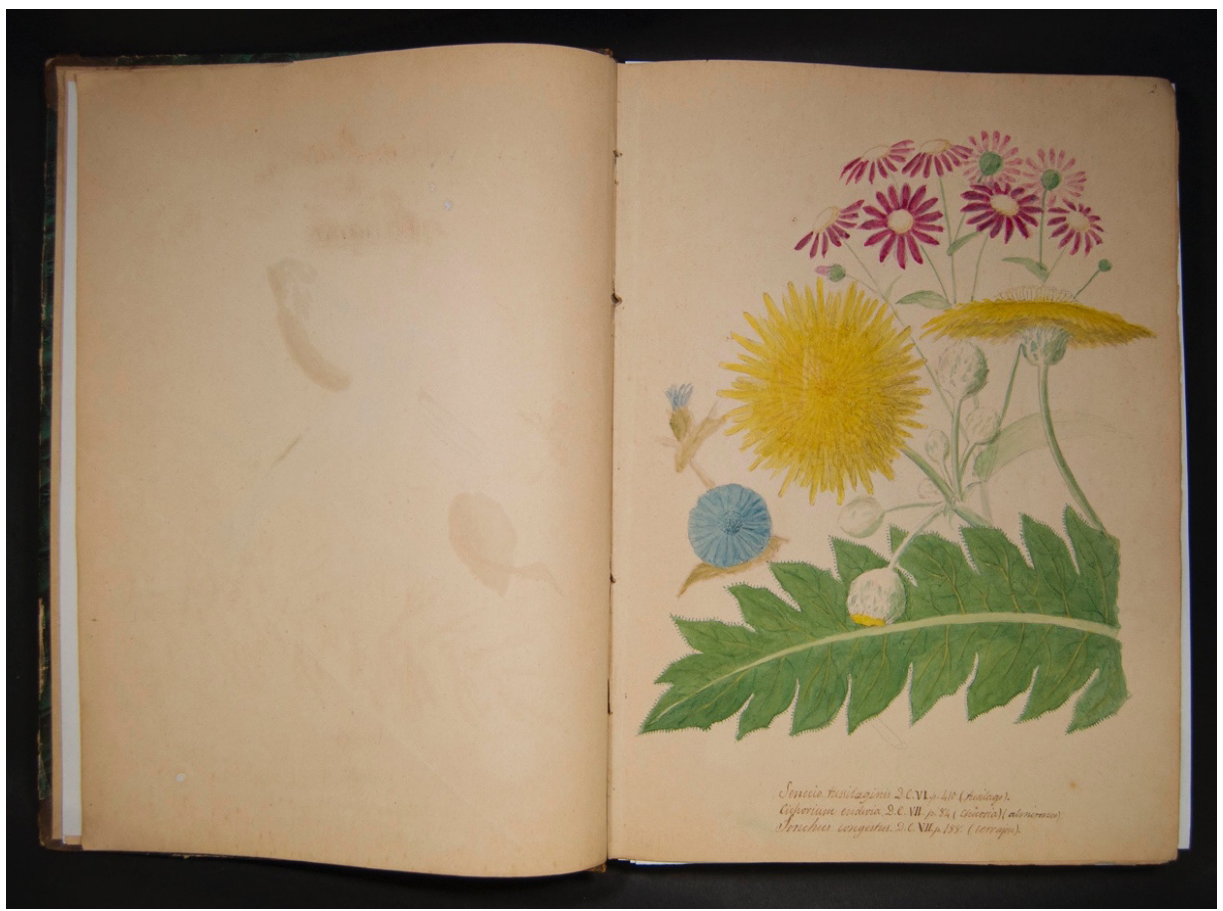

Figura 3. Senecio tussilaginis D.C.VI. p. 410 (tusilago), Cichorium endivia D.C.VII. p.84 (chicoria) (almirosses) y Sonchus congestus. D.C.VII. p. 188. (cerrajon). En la imagen se puede apreciar las degradaciones producidas en el reverso de la ilustración de la portada del álbum en la que se representa la Fringilla canaria, L. (tipo silvestre). Fuente: Autoras.
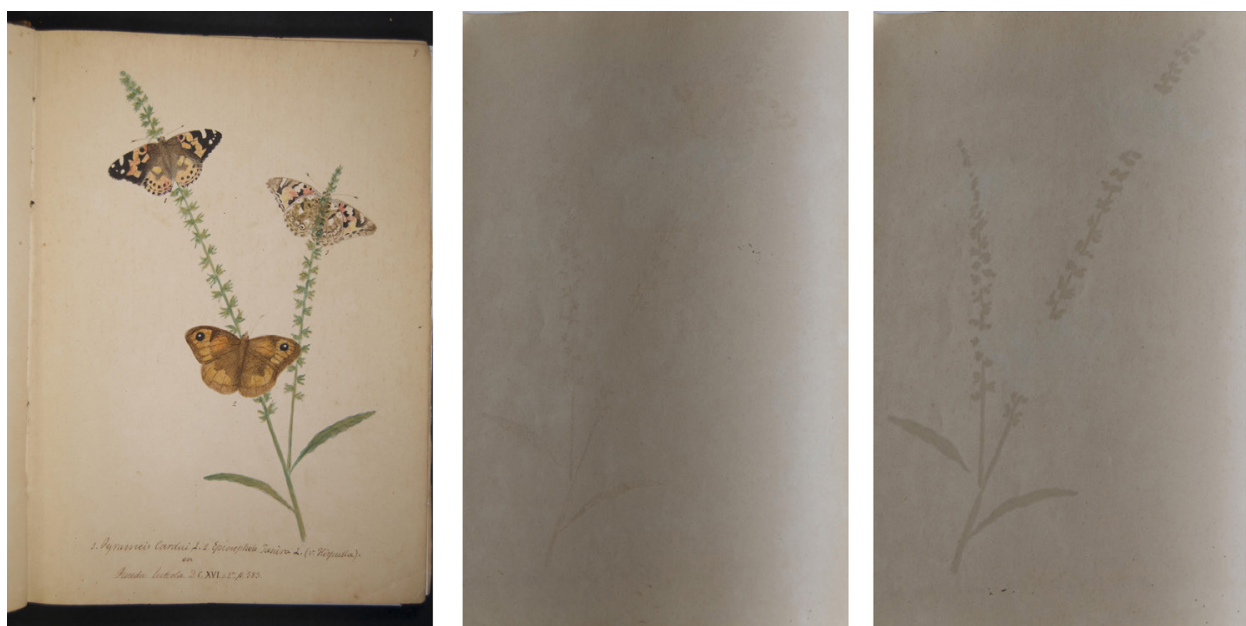

Figura 4. Ilustración de Ryrameis Cardui y Epinephele Tanira L. (v. Hispulla) sobre Reseda Luteola (izquierda). Degradaciones producidas en la hoja que entra en contacto directo con los procedimientos del dibujo (centro). Degradaciones producidas en el reverso de la hoja de la ilustración (derecha). En ambas imágenes (centro y derecha) se aprecia tanto zonas de oxidación como de reserva. Fuente: Autoras. 

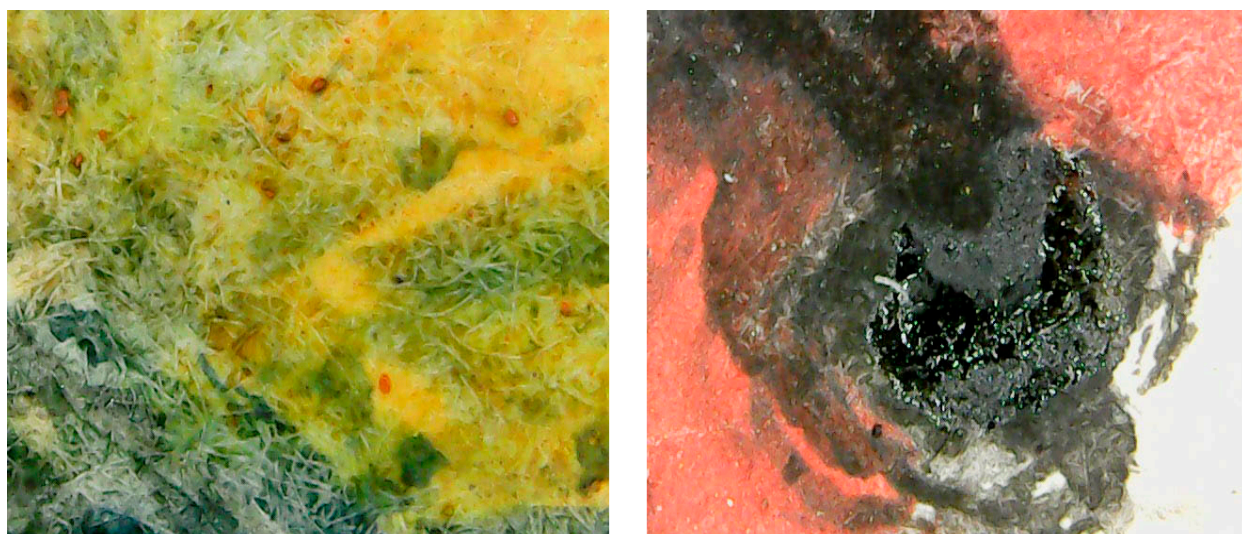

Figura 5. Detalle de la ilustración de la mariposa Colias edusa (pág. 9 del álbum) donde se observan pigmentos de diferentes granulometrías y opacidades, así como superposiciones (izquierda). Detalle el ojo de la ilustración del pájaro Fringilla carduelis,

Lin. (Pintado, Jilguero) (página 10 del álbum), donde se observa la utilización del procedimiento brillante (derecha). Fuente: Autoras.
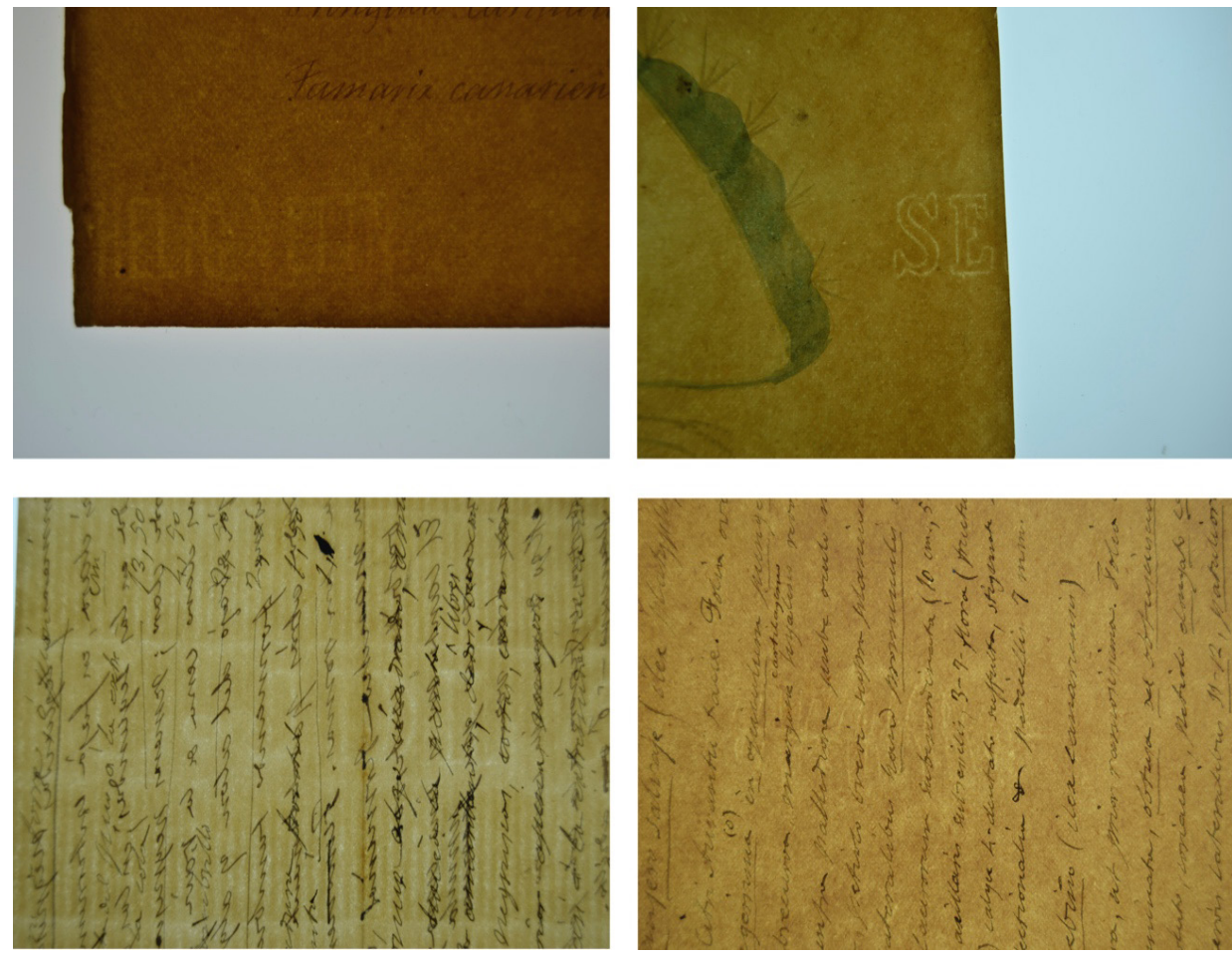

Figura 6. Folio $\mathrm{n}^{\mathrm{o}} 10$ (izquierda, arriba). Folio $\mathrm{n}^{\mathrm{o}} 34$ (derecha, arriba). Folio $\mathrm{n}^{\mathrm{o}} 39$ (izquierda, abajo). Folio n 31 (derecha, abajo). En estas cuatro imágenes se puede observar las diferentes tipologías de papel, así como las cuatro filigranas y diferentes marcas de agua como las verjuras de la lámina 12. Fuente: Autoras. 

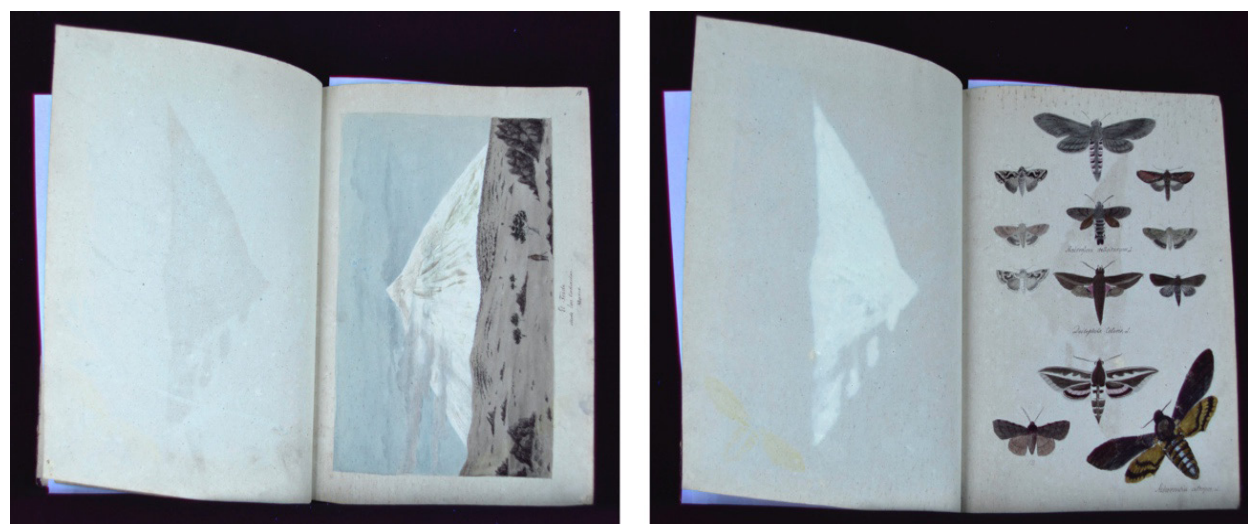

Figura 7. Ilustración del Teide. En las imágenes podemos observar la degradación que produce en la hoja con la que entra en contacto (izquierda). Reverso de la hoja en la que se encuentra la ilustración del Teide. Se puede observar la fluorescencia blanca producida por la degradación ocasionada por el procedimiento, así como la oxidación en la página de las siguientes ilustraciones. A su vez, en la esquina inferior izq. de la página izq., se aprecia la fluorescencia amarillo-anaranjada producida por la ilustración Archevontiu atropos, L. (derecha). Fuente: Autoras.

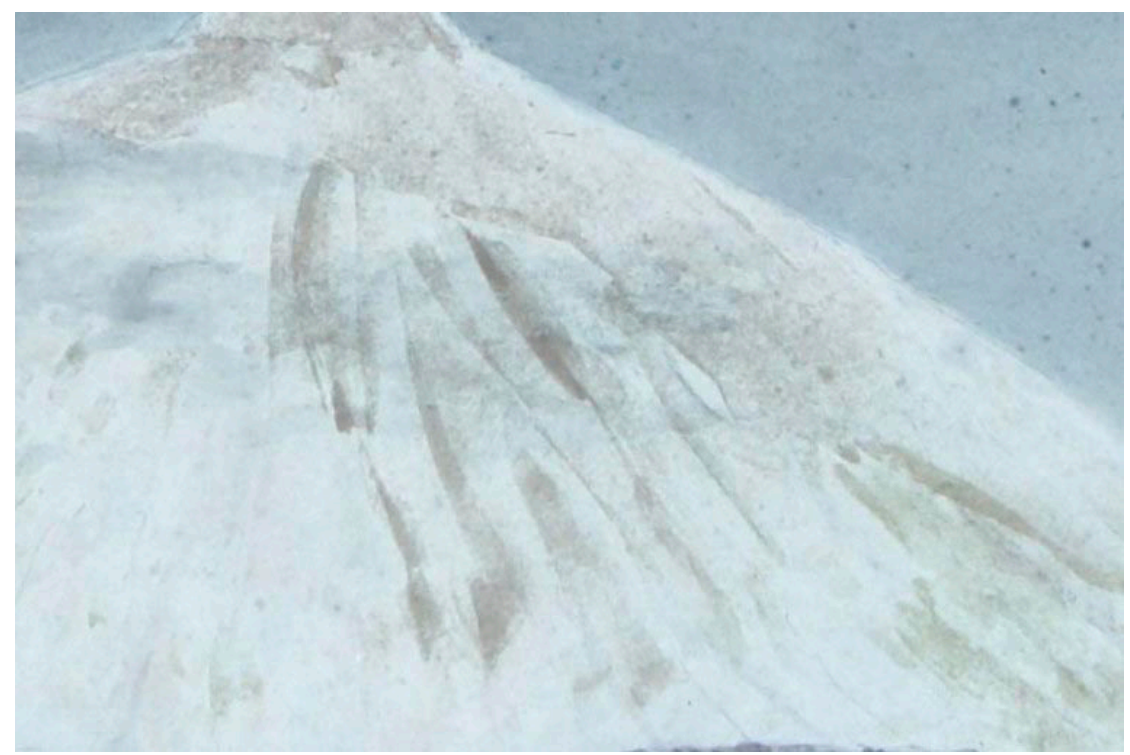

Figura 8. Detalle de la ilustración del Teide donde se aprecian las dos clases de fluorescencias de pigmento blanco. Fuente: Autoras. 

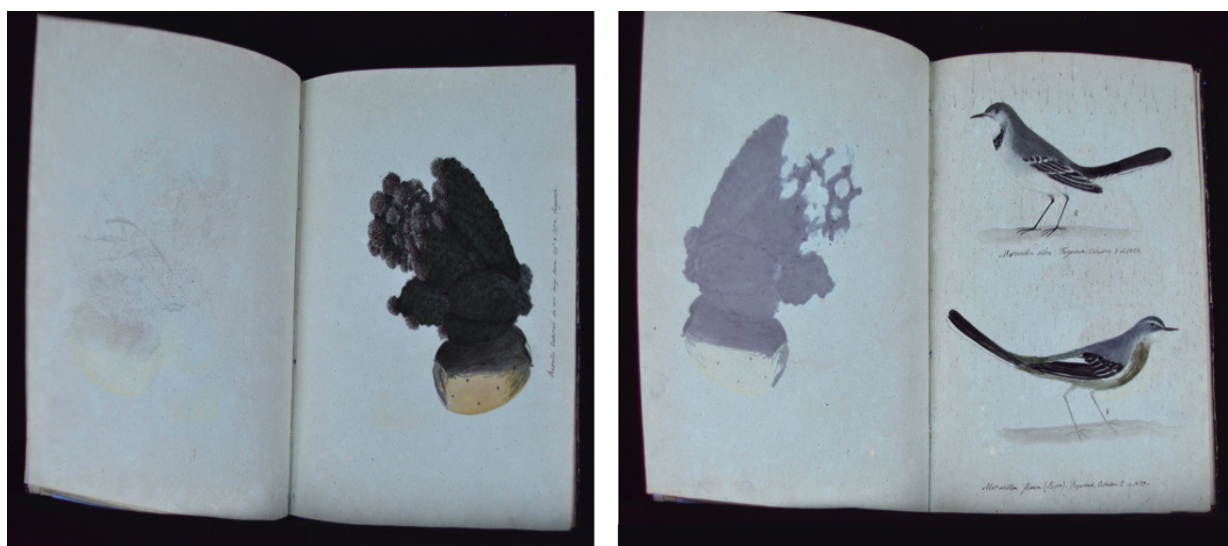

Figura 9. En el caso del retoño lateral del higo tuno, se puede visualizar más aquellas zonas pintadas con una técnica que transmite una fluorescencia opaca (las zonas verdes y que producen acidez tanto en el soporte anterior como en el propio) comparada con otras que no transmiten casi fluorescencia (las flores del higo) y que, sin embargo, por el reverso del soporte transmiten una fluorescencia blanca por la reserva que crean (izquierda). Por último, el color amarillo, destaca notablemente y como deja una mancha amarillenta tanto en el reverso de su soporte como en el del folio con el que entra en contacto (derecha). Fuente: Autoras.
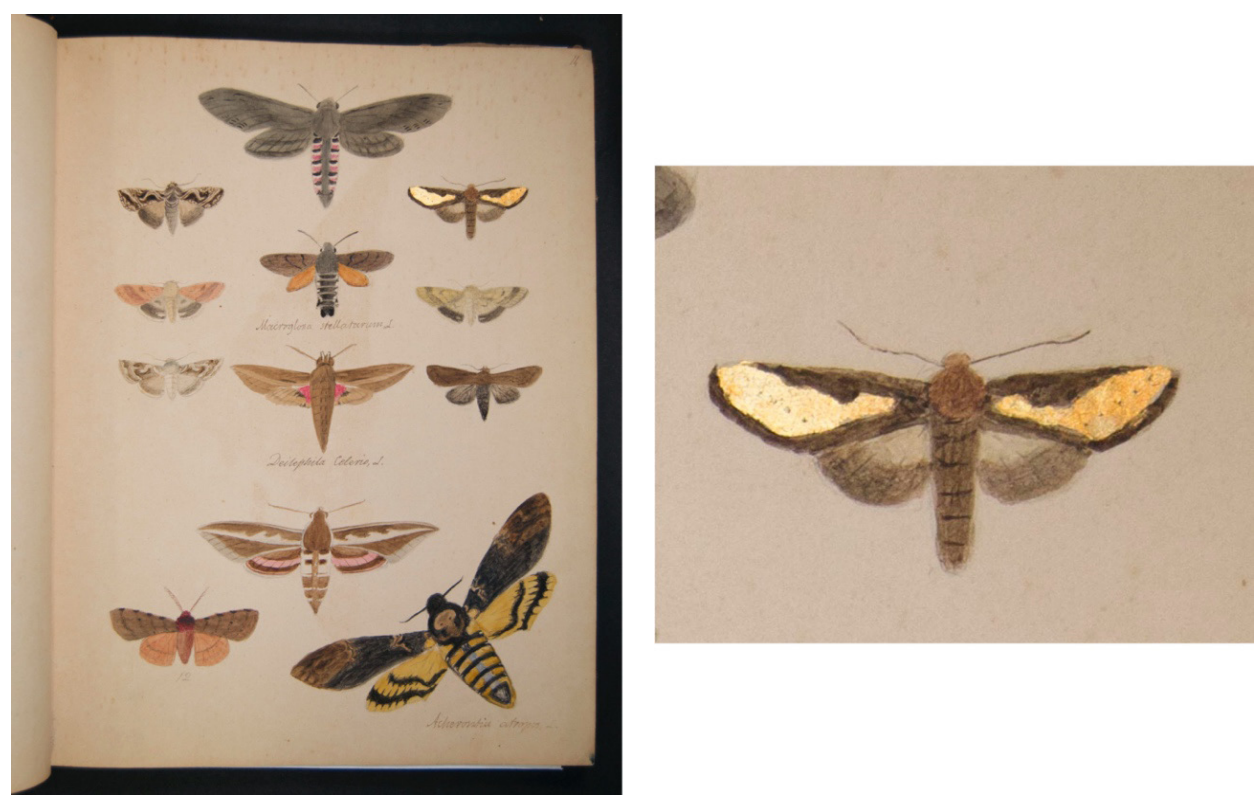

Figura 10. Las ilustraciones de la página 14 del cuaderno representan diferentes especies de lepidópteros; Macroglossa stellatarum, L., Deilephila Celeris, L. y Archevontiu atropos, L. (izquierda). Detalle de Macroglossa stellatarum, L., que presenta en las alas superiores una pequeña superficie decorada con pan de oro (derecha). Fuente: Autoras. 
